\title{
Thrombin Generation Measurement in Factor VII-Depleted Plasmas Compared to Inherited Factor VII-Deficient Plasmas
}

\author{
Muriel Giansily-Blaizot ${ }^{a}$ Raed Al Dieri ${ }^{\mathrm{b}}$ Jean-François Schved ${ }^{\mathrm{a}}$ \\ aLaboratoire Central d'Hématologie, Centre Hospitalier Universitaire, Montpellier, France; \\ bSynapse Laboratory, Cardiovascular Research Institute CARIM, University of Maastricht, The Netherlands
}

\section{Key Words}

Activated factor VII · Factor VII · Thrombin generation test · Factor VII deficiency

\begin{abstract}
Activated factor VII (FVIla)/tissue factor enzyme complex is the initiator of the coagulation cascade in vivo. FVIla is of particular interest because it has been found to induce haemostasis in various bleeding disorders. In order to evaluate the FVII threshold that is required to initiate the clotting cascade, we measured thrombin generation in FVII-depleted plasmas spiked with increasing amounts of normal pooled plasma and in inherited FVII-deficient plasmas. According to the literature, only trace amounts of FVII are sufficient to initiate blood coagulation in vitro. By contrast, results on inherited FVII-deficient plasmas showed a wide variety of the amounts of thrombin generated in plasmas with the same FVII coagulant activity levels. This suggests that the threshold of FVII required to initiate haemostasis in vivo depends on one or more, hitherto unknown, plasmatic or cellular factors.
\end{abstract}

Copyright @ 2003 S. Karger AG, Basel

\section{Introduction}

Human factor VII (FVII) plays a key role in the initiation of blood coagulation. In its zymogen form, FVII is a single chain glycoprotein produced by the liver. Its plasma concentration is one of the lowest among vitamin-Kdependent serine protease zymogens, $\sim 10 \mathrm{n} M$. Its activation involves the hydrolysis of a single peptide bond, yielding a light and a heavy chain linked by a unique disulphide bond [1]. Activated FVII (FVIIa) is unusual in two ways. (1) It continuously circulates in plasma as an unbound two-chain form, and (2) it remains in a zymogen-like state after proteolytic cleavage and becomes an efficient catalyst only when associated with tissue factor. On injury, the FVIIa/tissue factor complex triggers coagulation by activating the zymogens factor IX and factor X, ultimately resulting in the generation of thrombin, with its diverse haemostatic and thrombotic functions [2, 3].

FVIIa is in the focus of interest because it appears to be an effective mode of treatment for haemophilia patients (A and B) with inhibitors [4, 5]. Moreover, it has been successfully used in correcting the coagulopathy of patients with inherited FVII deficiency [6, 7] and of patients with thrombocytopenia [8]. A better understanding of the

Dr. Muriel Giansily-Blaizot

Laboratoire d'Hématologie, CHU de Montpellier

80 avenue Augustin Fliche

FR-34295 Montpellier Cedex (France)

Tel. +334673370 33, Fax +334673370 36, E-Mail m-giansily@chu-montpellier.fr 
first step of the coagulation cascade would be useful for managing such FVIIa treatments. Therefore, we tried to determine the threshold levels of FVII that can initiate blood coagulation under physiological and pathological conditions. As the whole haemostatic network is engaged in generation and subsequent inactivation of thrombin [9], we used thrombin generation as an indicator of the activity of the coagulation system. We determined the effect on thrombin generation of small amounts of FVIIa added to plasma in which FVII was absent. In an attempt to avoid artifacts that might be introduced by depleting FVII in normal plasma we compared depleted normal plasma to congenitally deficient plasmas.

\section{Patients and Methods}

\section{Plasma Collection}

The control plasma was obtained by pooling plasmas from 40 apparently healthy males and females, which was stored at $-80^{\circ} \mathrm{C}$. It was arbitrarily assigned a value of $100 \%$ FVII. FVII-depleted plasma was obtained from freeze-dried citrated human plasmas from which FVII had been removed by selective immunoadsorption (Diagnostica Stago, Asnières, France). The panel of deficient samples consisted of 13 patients with inherited FVII deficiency. Among them, 4 were brothers and sisters. Plasmas were obtained by collecting venous blood in $1 / 10 \mathrm{vol} 0.129 \mathrm{~mol} / \mathrm{l}$ trisodium citrate-evacuated tubes with centrifugation at 2,000 $\mathrm{g}$ for $20 \mathrm{~min}$. They were sent frozen in dry ice to the central laboratory where the phenotype analyses were performed.

\section{Coagulation Assays}

FVII:Ag levels were determined by enzyme-linked immunosorbant assays using the Asserachrom ${ }^{\mathrm{TM}}$ FVII:Ag kit (Diagnostica Stago). FVII coagulant activity (FVII:C) was assayed by a one-stage method based on the prothrombin time using human recombinant thromboplastin (Recombiplastin ${ }^{\mathrm{TM}}$ Instrumentation Laboratory, Lexington, Mass., USA), FVII-deficient plasma (Diagnostica Stago) as a substrate, and a control plasma as a calibrator.

\section{Thrombin Generation Measurement}

Thrombin generated was assessed by a subsampling method as previously described [10]. Briefly, $240 \mu \mathrm{l}$ of defibrinated plasma and $60 \mu \mathrm{l}$ of buffer A $(0.05 M$ Tris- $\mathrm{HCl}, 0.1 M \mathrm{NaCl}, 0.05 \%$ BSA, $\mathrm{pH}$ 7.35) containing recombinant tissue factor with phospholipid vesicles were incubated for $5 \mathrm{~min}$ at $37^{\circ} \mathrm{C}$. Then, $60 \mu \mathrm{l}$ of $\mathrm{CaCl}_{2} 0.1 \mathrm{M}$ was added to start the reaction. At regular time intervals, $10-\mu 1 \mathrm{sam}-$ ples were withdrawn and transferred into $490 \mu \mathrm{l}$ of buffer B $(0.05 \mathrm{M}$ Tris- $\mathrm{HCl}, 0.1 M \mathrm{NaCl}, 0.05 \%$ BSA, $20 \mathrm{~m} M$ EDTA, $\mathrm{pH}$ 7.9) containing $200 \mu \mathrm{M}$ S2238 (Chromogenic AB, Malmö, Sweden). After 2 min the reaction is stopped by adding $300 \mu \mathrm{l}$ of $1 M$ citric acid. Finally, the optical density is read at $405 \mathrm{~nm}$. Thrombin generation curves were constructed with the OD as a function of time.

\section{Results}

\section{Thrombin Generation Measurement in FVII-Depleted} Plasmas

We investigated thrombin generation in FVII-depleted plasma spiked with increasing amounts of control plasma ranging from 0.5 to $10 \%$ (fig. 1). No thrombin formation was observed for over 30 min when no normal plasma was added. A decrease in lag phase and an increase in both peak height and endogenous thrombin potential (ETP) were induced by spiking with $1 \%$ normal plasma and increased proportionally with the amount added to become near normal at $10 \%$ of normal plasma. The lag phase normalized already at $2.5 \%$ of FVII, ETP and peak height follow.

\section{Thrombin Generation Measurement in Inherited FVII-Deficient Plasmas}

No relation could be established between FVII:C and the parameters of the thrombogram (lag phase, peak height and ETP), except for kindred. Indeed, large discrepancies were observed between plasmas displaying the same FVII:C levels. Patients A and B (FVII:C: 2.5\%) showed higher ETP values than patients $\mathrm{C}$ and D (FVII:C: 2.7 and $3.5 \%$, respectively). In fact patients $\mathrm{A}$ and $\mathrm{B}$ showed a higher thrombin generation than depleted plasma spiked with $2.5 \%$ normal plasma and patients $\mathrm{C}$ and $\mathrm{D}$ a lower one. Patients $\mathrm{C}$ and $\mathrm{D}$ also displayed longer lag time values than the relevant FVII-depleted plasma (fig. 2a). In the same way, inherited FVII-deficient plasmas with FVII:C $>7.5 \%$ showed normal lag phases but various ETP and peak height levels (fig. 2b). In contrast, the difference between thrombograms within the same FVII-deficient family was small or even non-existent (fig. 3).

\section{Discussion}

In order to determine the threshold value of FVII necessary to provoke thrombin generation, we spiked FVIIdepleted plasmas with increasing amounts of normal control plasma and compared the results to those obtained with inherited FVII-deficient plasmas, containing various amounts of residual FVII activity.

No thrombin generation was observed in FVII-depleted plasma as such, indicating virtual absence of contact activation in our system. These results are consistent with FVII gene knockout experiments in mice. FVII-/mice die during the first days of life because of severe

Pathophysiol Haemost Thromb 2003;33:36-42 
Fig. 1. Thrombin generation measurement of FVII-depleted plasmas spiked with increasing amounts of normal pooled plasmas. ETP and peak height parameters are expressed as percentages of the control. Curves in order from bottom to top.

\begin{tabular}{lccc}
\hline Spiked FVII, \% & Lag time, s & ETP, \% & Peak, \% \\
\hline 0 & $<1,200$ & 0 & 0 \\
1 & 3.1 & 32 & 28 \\
2.5 & 0.5 & 59 & 50 \\
5 & 0.5 & 88 & 63 \\
10 & 0.5 & 96 & 84 \\
Control & 0.5 & 100 & 100 \\
\hline
\end{tabular}

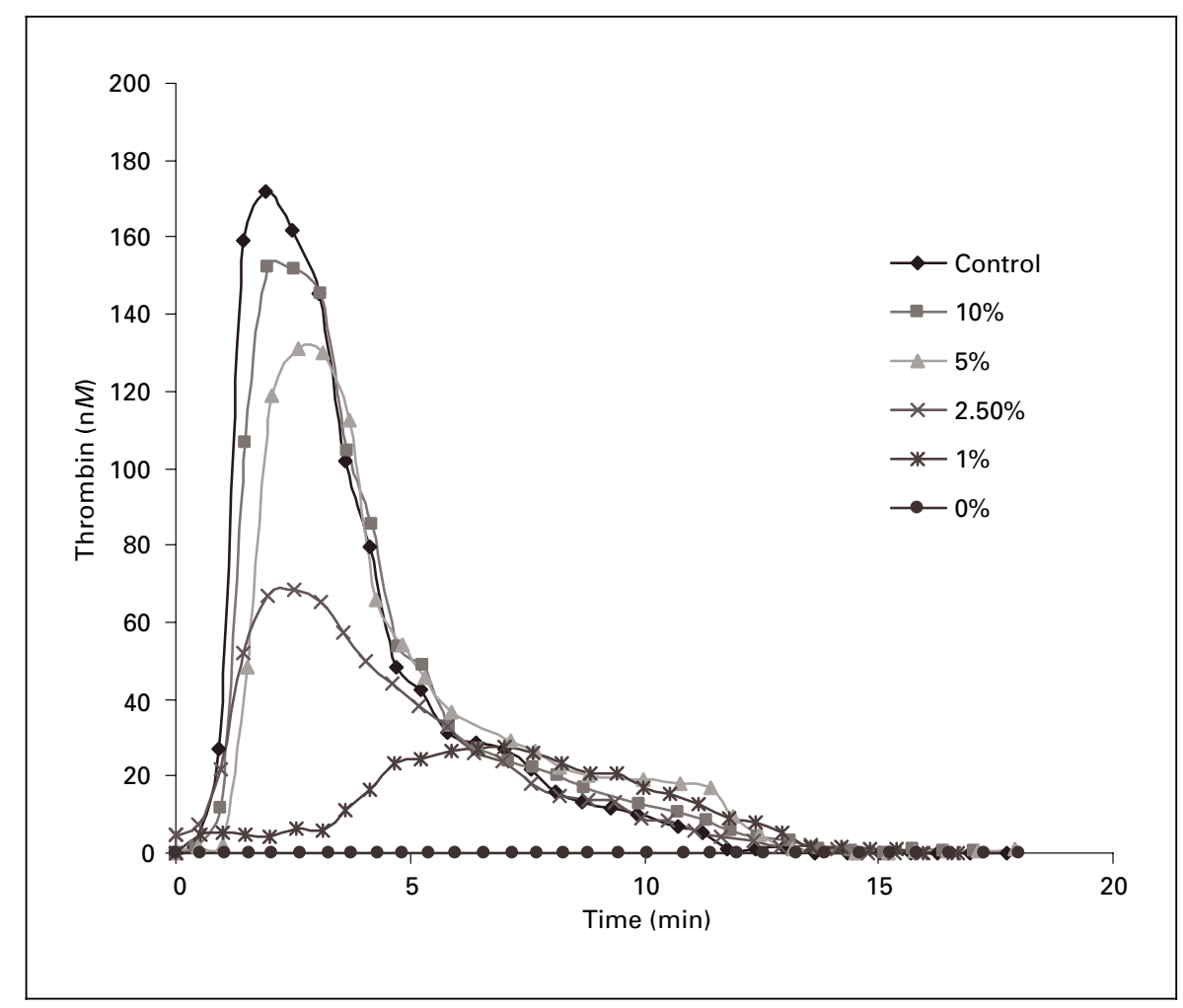

haemorrhages [11]. Indeed in inherited FVII deficiency, those FVII gene mutations that are incompatible with the generation of FVIIa were associated with severe bleeding phenotypes [12]. We cannot exclude the possibility, however, that endothelial cells or platelets allow thrombin to be produced through compensating mechanisms that are not represented in our experimental setup, which only comprises platelet-poor plasma.

Spiking FVII-depleted plasma with increasing concentrations of normal pooled plasma led to a measurable generation of thrombin already when less than $1 \%$ of normal plasma was added (not shown). The addition of $2.5 \%$ of control plasma was sufficient to normalize the lag phase which is equivalent to the clotting time. During the lag time, traces of thrombin are formed causing explosive thrombin formation through feedback activation pathways and then leading to the clot [9]. These results are also in agreement with literature data. Empirical and mathematical modeling studies suggest that as little as $5 \mathrm{pmol} / \mathrm{l}$, which represents only $0.05 \%$ of the normal FVII plasma level, is sufficient to trigger the clotting cascade $[13,14]$. Both ETP and peak height reached near normal values when $10 \%$ of control plasma were added to the FVII- depleted plasma. These data are consistent with patients with inherited FVII deficiency (FVII:C $<10 \%$ ) reported in the literature who did not experience excessive bleeding after surgery carried out without replacement therapy $[15,16]$. Both ETP and peak height parameters inform about the amount of total generated thrombin and give relevant information on the haemostatic status of tested plasmas $[17,18]$. The peak height represents the velocity of thrombin production. The ETP represents what thrombin is potentially available during its life time to accomplish haemostatic functions at and about the site of a lesion.

However, thrombin generation curves measured in inherited FVII-deficient plasmas showed large variations either in lag time values for FVII levels ranging from 2.5 to $3.5 \%$, or in both ETP and peak heights for FVII levels ranging from 7.5 to $10.5 \%$. These results were confirmed in larger series of patients [19]. We think that it is less likely that these variations are due to a variation in the preanalytical conditions. Indeed, because FVII deficiency is a rare disorder, plasmas were obtained from different laboratories so that blood collection and preparation as well as transportation conditions differed. However, sam- 


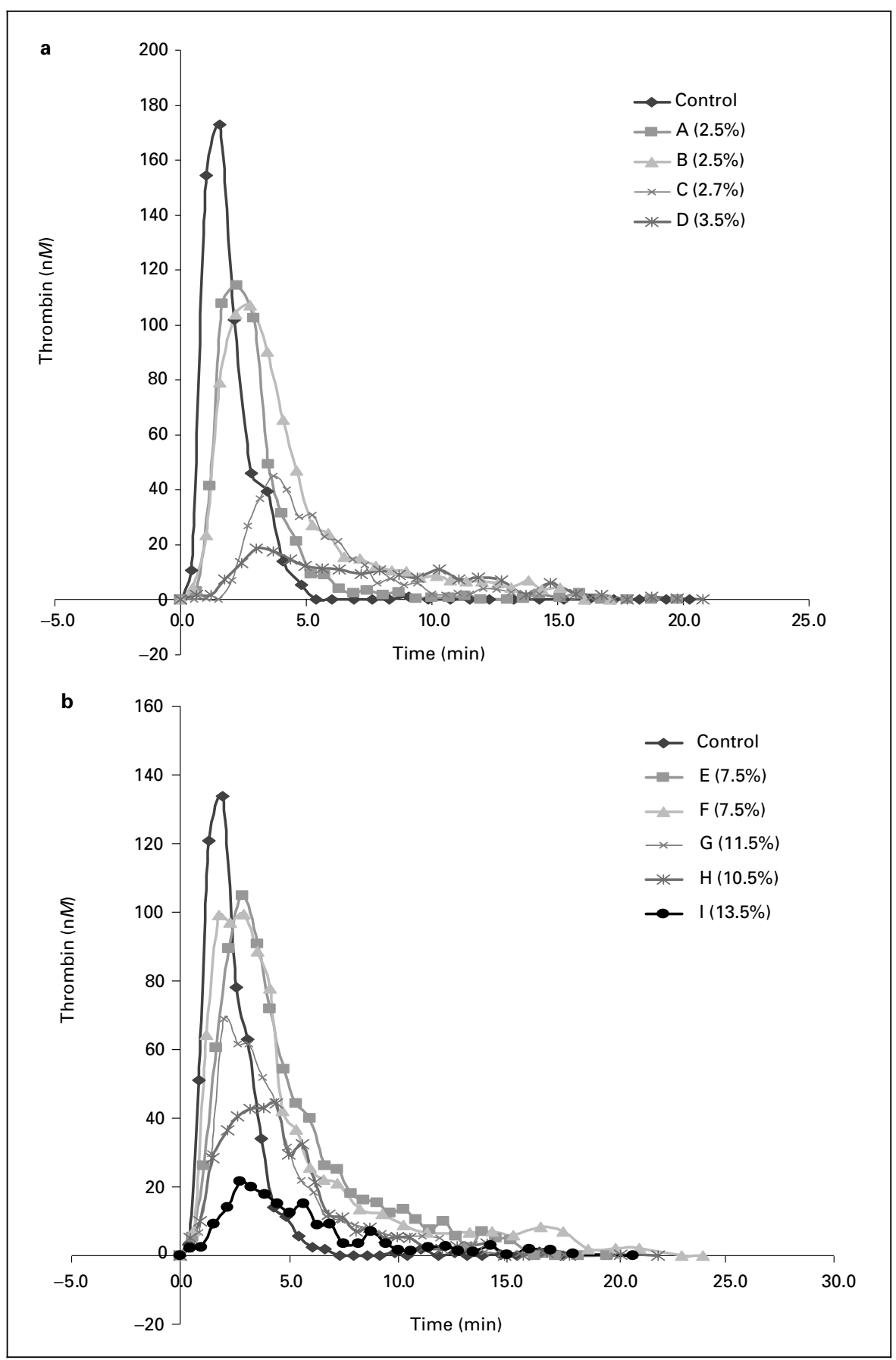

Fig. 2a, b. Thrombin generation measurement of inherited FVIIdeficient plasmas

\begin{tabular}{llllrl}
\hline Patients & VII:C, $\%$ & VII:Ag, $\%$ & Lag, $s$ & ETP, $\%$ & Peak, \% \\
\hline A & 2.5 & 17 & 0.6 & 80 & 71 \\
B & 2.5 & 40 & 0.5 & $<100$ & 62 \\
C & 2.7 & 37 & 1.5 & 62 & 30 \\
D & 3.5 & 2 & 1.8 & 48 & 11 \\
E & 7.5 & 65 & 0.6 & $<100$ & 63 \\
F & 7.5 & 76 & 0.6 & $<100$ & 58 \\
G & 11.5 & 44 & 0.5 & 82 & 33 \\
H & 10.5 & 42 & 0.5 & 95 & 51 \\
I & 13.5 & 55 & 0.5 & 51 & 16 \\
\hline
\end{tabular}

FVII Amounts for Plasmatic Thrombin

Pathophysiol Haemost Thromb 2003;33:36-42 


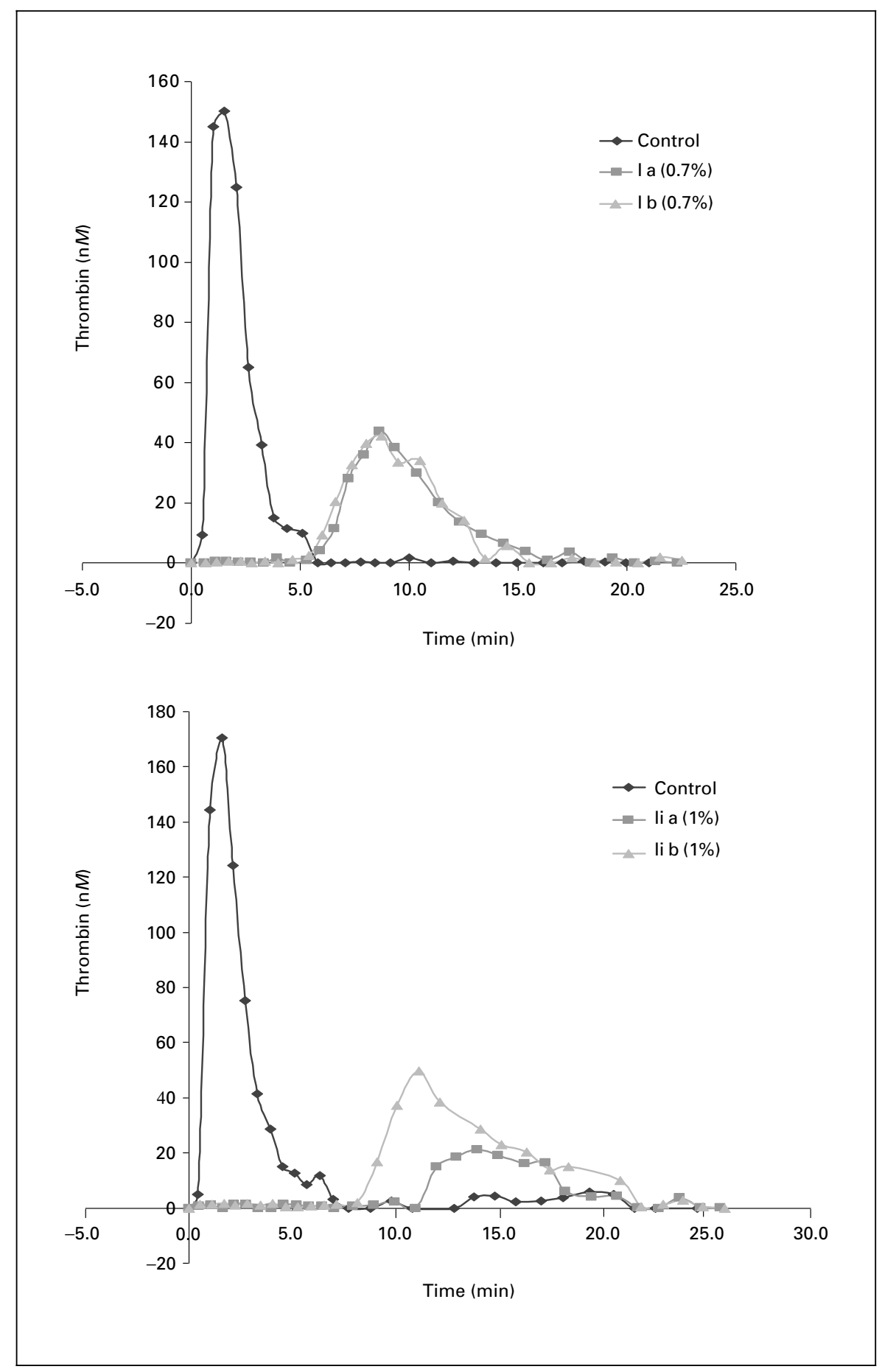

Fig. 3. Thrombin generation measurement in kindred with inherited FVII deficiency

\begin{tabular}{llcccl}
\hline Patients & VII:C & VII:Ag & Lag time & ETP & Peak height \\
\hline Ia & 0.7 & 8 & 6 & 73 & 28 \\
Ib & 0.7 & 8 & 5.9 & 75 & 29 \\
Iia & 1 & 52 & 11.9 & 31 & 12 \\
Iib & 1 & 47 & 9.1 & 85 & 29 \\
\hline
\end{tabular}


ples from kindred collected from two different laboratories at different times showed exactly the same thrombin generation curves (fig. 3). The discrepancies observed might be explained in different ways: (1) In our in vitro model, FVII-depleted plasmas were obtained by pooling plasmas from numerous donors. Therefore, every clotting-activating or regulating factor reached normal values. Concerning FVII-deficient plasmas, private variations in the function or concentration of one of these factors might be observed. For FVII-deficient plasmas, even if no other clotting factor deficiency was documented, borderline values could influence the haemostatic equilibrium. (2) Inherited FVII deficiency is characterized by a wide genotypic heterogeneity. Up to 80 mutations are reported in the human FVII mutation database (http://www.europium.csc.mrc.ac.uk) [20]. Most of these are missense mutations leading to decreased secretion and/or altered function of FVII. The molecular heterogeneity of the dysfunctional FVII variants might explain the discrepancies observed between plasmas with apparently the same FVII:C. It should be noted that the FVII:C in the plasma of the patients has been determined via a one-stage technique that, essentially, is a measurement of the lag time of thrombin generation (=clotting time). It is conceivable that the influence of different mutations on the lag time and on the bulk of thrombin generation is not necessarily similar. The next question is whether the lag time or the ETP better represents the clinical picture.
In conclusion, under 'in vitro circumstances', it is generally found that only trace amounts of FVII are required to initiate the blood coagulation cascade. Under 'in vivo circumstances', no FVII level threshold could be accurately defined because of individual variations of other known or unknown factors. We assume that parameters other than FVII itself influence thrombin generation in inherited FVII deficiencies.

The fundamental question can be reduced to the following: What are the variations in level and function of FVII as well as of other known and unknown factors in plasma that make that there is an apparent discrepancy between the FVII level as determined by lag time measurements (clotting times) and by the peak or the total amount of thrombin formed?

For the clinician the practical question remains of what parameter best represents the clinical condition. The available data [9] and the known fact that the clinical condition does not always correlate with the residual amount of FVII as determined from clotting times suggest that the peak and/or the ETP might be the more relevant parameters.

\section{Acknowledgements}

The authors would like to thank the study group with FVII deficiency for providing the plasma samples.

\section{References}

1 Davie EW, Fujikawa K, Kisiel W: The coagulation cascade: Initiation, maintenance, and regulation. Biochemistry 1991;30:10363-10370.

2 Higashi S, Nishimura H, Fujii S, Takada K, Iwanaga $S$ : Tissue factor potentiates the factor VIIa-catalysed hydrolysis of an ester substrate. J Biol Chem 1992;267:17990-17996.

3 Bauer KA: Activation of the factor VII-tissue factor pathway. Thromb Haemost 1997;78: 108-111.

4 Hay CRM, Negrier C, Ludlam CA: The treatment of bleeding in acquired haemophilia with recombinant factor VIIa: A multicentre study. Thromb Haemost 1997;78:1463-1467.

5 Hedner U, Bjoern S, Bernvil SS, Tengborn L, Stigebdahl L: Clinical experience with human plasma-derived factor VIIa in patients with hemophilia A and high titer inhibitors. Haemostasis 1989;19:335-343.

6 Mariani G, Testa MG, Di Paolantonio T, Molskov Bech R, Hedner U: Use of recombinant, activated factor VII in the treatment of congenital factor VII deficiencies. Vox Sang 1999; 77:131-136.
7 Hunault M, Bauer KA: Recombinant factor VIIa for the treatment of congenital factor VII deficiency. Semin Thromb Hemost 2000;26: 401-405.

8 Kristensen J, Killander A, Hippe E, Helleberg C, Ellegard J, Holm M, Kutti J, Mellqvist UH, Johansson JE, Glazer S, Hedner U: Clinical experience with recombinant factor VIIa in patients with thrombocytopenia. Haemostasis 1996;26(suppl 1):159-164.

9 Hemker HC: Thrombin generation, an essential step in haemostasis and thrombosis; in Bloom Al, Forbes CD, Thomas DP, Tuddenham EGD (eds): Haemostasis and Thrombosis. Edinburgh, Churchill Livingstone, 1993, pp 477-490.

10 Hemker HC, Willems GM, Béguin S: A computer assisted method to obtain the prothrombin activation velocity in whole plasma independent of thrombin decay process. Thromb Haemost 1986;56:9-17.
11 Rosen ED, Chan JC, Idusogie E, Clotman F, Vlasuk G, Luther T, Jalbert LR, Albrecht S, Zhong L, Lissens A, Schoonjans L, Moons L, Collen D, Castellino FJ, Carmeliet P: Mice lacking factor VII develop normally but suffer fatal perinatal bleeding. Nature 1997;390:290_ 293.

12 Giansily-Blaizot M, Aguilar-Martinez P, Biron-Andreani C, Jeanjean $\mathrm{P}$, Igual $\mathrm{H}$, Schved JF: Analysis of the genotypes and phenotypes of 37 unrelated patients with inherited factor VII deficiency. Eur J Hum Genet 2001;9:105112.

13 Lawson JH, Kalafatis M, Stram S, Mann KG: A model for the tissue factor pathway to thrombin. An empirical study. J Biol Chem 1994; 269:23357-23366.

14 Butenas S, Van't Veer C, Mann KG: 'Normal' thrombin generation. Blood 1999;94:21692178 . 
15 Orke AJ, Mant MJ: Factor VII deficiency and surgery: Is preoperative replacement therapy necessary? JAMA 1977;5:424-425.

16 Giansily-Blaizot M, Biron-Andréani C, Aguilar-Martinez P, de Moerloose P, Briquel ME, Goudemand J, Stieltjes N, Barrot C, Chambost H, Durin A, Gay V, Peynet J, Pouymayou K Schved JF: Inherited factor VII deficiency and surgery: Clinical data are the best criteria to predict the risk of bleeding. $\mathrm{Br} \mathrm{J}$ Haematol 2002;117:172-175.
17 Hemker HC, Wielders S, Kessels H, Béguin S: Continuous registration of thrombin generation in plasma, its use for the determination of the thrombin potential. Thromb Haemost 1993;70:617-624.

18 Wielders S, Mukherjee M, Michiels J, Rijkers DTS, Cambus JP, Knebel RWC, Kakkar V, Hemker HC, Béguin S: The routine determination of the endogenous thrombin potential, first results in different forms of hyper- and hypocoagulability. Thromb Haemost 1997;77: 629-636.
19 Al Dieri R, Peyvandi F, Santagostino E, Giansily M, Mannucci PM, Schved JF, Béguin S, Hemker HC: The thrombogram in rare inherited coagulation disorders: Its relation to clinical bleeding. Thromb Haemost 2002;88:576582.

20 McVey J, Boswell E, Mumford AD, KemballCook G, Tuddenham EGD: Factor VII deficiency and the FVII mutation database. Hum Mutat 2001;17:3-17. 